\title{
A typology of community flood resilience
}

\section{Finn Laurien ${ }^{1}$ (1) $\cdot$ Stefan Hochrainer-Stigler ${ }^{1}$. Adriana Keating ${ }^{1} \cdot$ Karen Campbell $^{2} \cdot$ Reinhard Mechler $^{1}$. Jeffrey Czajkowski ${ }^{3}$}

Received: 18 June 2019 / Accepted: 16 January 2020 / Published online: 17 February 2020

(C) The Author(s) 2020

\begin{abstract}
Flood risk is increasing worldwide and there is a growing need to better understand the co-benefits of investments in disaster resilience. Utilizing a multinational community flood resilience dataset, this paper takes a systems approach to understanding community-level flood resilience. Using a cluster analysis and bivariate correlation methods, we develop a typology of community flood resilience capacity based on community characteristics and five capitals (human, financial, natural, physical, and social). Our results reinforce the importance of context-specific policymaking and give recommendations of four distinct clusters to investigate the relationship between flood resilience and prevailing development conditions. We especially find that communities with higher interactions between their capital capacities tend to have higher flood resilience levels. Additionally, there are indications that stronger interactions between community capacities can help to induce multiple co-benefits when investing in disaster resilience. Our results also have important policy implications on the individual community level. For example, based on our results, we suggest that communities with lower flood resilience capacities and interactions can best build resilience on leveraging their relatively higher human capital capacities to strengthen the financial and social capitals. Negative effects might happen for urban communities when co-benefits of natural and physical capital are not fully integrated. The highest flood resilience capacity is found in communities with a well-balanced household income distribution which is likely a contributing factor to the importance of financial capital for this cluster. Our results emphasize the importance of an integrative approach to management when implementing systematic flood disaster resilience metrics and development measures.
\end{abstract}

Keywords Community $\cdot$ Disaster resilience $\cdot$ Measurement $\cdot$ Standardized metric $\cdot$ Data collection $\cdot$ Cluster analysis

\section{Introduction}

The collection of quantitative baseline estimates to track progress in disaster resilience is seen, similar to the Sustainable Development Goals, as a requirement for success in reducing risk and achieving sustainable development (UNISDR 2015).

Communicated by Xiangzheng Deng

Finn Laurien

laurien@iiasa.ac.at

Stefan Hochrainer-Stigler

hochrain@iiasa.ac.at

Adriana Keating

keatinga@iiasa.ac.at

Karen Campbell

karen.Campbell@ihsmarkit.com

Reinhard Mechler

mechler@iiasa.ac.at
However, while some detailed quantitative analysis of selected resilience indicators can be found either on the household (Jones and Tanner 2017; Tambo and Wünscher 2017) or regional level (Adger et al. 2005; Cutter 2016; Lam et al. 2015; Parsons et al. 2016), especially in the case of disasters, there are only a handful of community-based resilience studies

Jeffrey Czajkowski

jczajkowski@naic.org

1 International Institute for Applied System Analysis, Risk and Resilience Program, Schlossplatz 1, A-2361 Laxenburg, Austria

2 IHS Markit Global, Division: Economics and Country Risk, 4th floor Ropemaker Place, 25 Ropemaker Street, EC2Y 9LY London, England

3 National Association of Insurance Commissioners, Center for Insurance Policy and Research, 64106 Kansas, USA 
available (Cutter et al. 2014; Twigg 2009). These studies usually look at one or two communities at most and hence do not generate the data required to identify and analyze generalizable insights about interactions between community assets or characteristics. Indeed, the community level is a dynamic complex system with many interactions at lower "levels" (e.g., individuals and groups within communities), capacities between local and national institutions, as well as beyond the community boundaries (e.g., municipality, national, or even global levels) (Cutter et al. 2008; Shaw 2006). The dynamic of all multiple interactions across scales is therefore an important element in measuring disaster resilience at the community level.

Estimates of disaster resilience that focus only on economic indicators and/or physical robustness attributes miss much of the complexity inherent to the community system and disaster resilience (Keating et al. 2016). This paper focuses on community flood resilience and aims to fill part of this gap by analyzing the relationships between community capitals using data from 118 communities of nine countries (including Afghanistan, Bangladesh, Haiti, Indonesia, Mexico, Nepal, Peru, Timor-Leste, and the USA). The focus on flooding is no coincidence as it is one of the most threatening disasters in terms of losses and damages worldwide with an increasing number of people exposed to flooding. Between 1970 and 2010 , the number people living in a flood prone community has almost doubled, and the estimated financial losses has multiplied tenfold in the last three decades (CRED 2018). The community level was chosen because most of the direct and indirect flood impacts happen at this level, and it is the level at which much effective action to build flood resilience can be taken.

In this paper, we begin to systematically assess resilience to flood events, using a holistic and system-based approach. Our dataset captures detailed multi-dimensional attributes of disaster resilience and provides consistent and reliable baseline estimates of community disaster resilience capacity (Campbell et al. 2019). We analyze this dataset using a multi-capacity approach that includes aspects of human, financial, social, natural and physical dimensions, as well as other socio-economic indicators.

As our standardized data on community flood resilience comes from multiple countries and contexts, collected in the years from 2015 to 2017 , it allows us to explore whether there are common community "types." In order to reduce complexity and understand the common characteristics of community resilience across contexts, we build a typology of community flood resilience. While we acknowledge that communities have specific characteristics and need local engagement for building resilience, finding a common typology of these characteristics could raise awareness and share learnings for community flood resilience.
We focused on one key question regarding disaster resilience at the community level, namely, what are the pre-event characteristics for different groups of communities based on their resilience capacities and socio-economic development that help build community flood resilience?

This paper is organized as follows. We first provide a background to the concept of disaster resilience and its measurement ("Concept of disaster resilience" section), followed by a description of the Flood Resilience Measurement for Communities (FRMC) framework and the tool for data collection and assessment ("Study area and data collection"section). We proceed to explain the methods used to analyze the data in "Method for analyzing community flood resilience clusters"section and present the results of the analysis in the "Results" section. In "Discussion: a typology of community flood resilience"section, we discuss the findings, and finally present a forward-looking perspective of the research agenda in this field.

\section{Concept of disaster resilience}

\section{A holistic concept}

The concept of resilience has been taken forward in multiple disciplines as emphasized by several literature reviews, including engineering (Davoudi et al. 2012; Holling 1996), socio-ecological systems (Holling 1973), psychology (Berkes and Ross 2013; Luthar 2006; Norris et al. 2008; Welsh 2014), and economics (Hallegatte 2014; Rose 2009). With increasing disaster risk owing to both climate change, extreme weather patterns and development dynamics that create greater exposure to risk, disaster resilience has moved into the limelight (Cutter et al. 2014; Keating et al. 2016; Manyena 2006; Ostadtaghizadeh et al. 2015). Applications of the concept to disasters have been discussed in the literature, and disaster resilience has come to the fore as a concept with the potential to help integrate disaster risk management, sustainable development and climate change adaptation concerns (Adger 2000; Béné et al. 2012; Berkes and Folke 1998; Keating et al. 2016). Broadly, these theorists argue that a holistic concept of resilience is needed for a better understanding of the interrelations between human, financial, natural, social, and physical systems.

Within the disasters field in particular, a multidimensional view of resilience being composed of several capacities is common. For example, Constas et al. (2014) identify resilience as a "multidimensional capacity." Capacity-focused approaches also align with the concept of sustainable development (Deneulin and Shahani 2009; Folke et al. 2002), for example, the five capitals of the sustainable livelihoods framework (DfID 1999), which further contribute to the integrative potential of the resilience. The five capitals approach picks up 
on linking disaster resilience with community development by assessing development beyond the economic perspective (DfID 1999; Keating et al. 2017). This approach recognizes that community functionalities are sometimes difficult to substitute with manufactured or economic capital and emphasizes the value of developing all community capacities. Community wellbeing-holistically conceptualized beyond economic indicators - is thus treated as stemming from a set of community capacities related to human, natural, social, financial, and physical spheres, where their interactions play a particularly important role in community wellbeing and development (Norris et al. 2008; Wilson 2010).

A holistic concept of resilience needs to consider empirical interactions between community capacities. Wilson (2010) provides a theoretical foundation for assessing empirical data from the perspective of multiple resilience capacities. He focuses on rural agricultural communities and highlights that these communities are more than a source of food and fiber production; they are also a source of environmental and social functionalities. In particular, he emphasizes the relevance of multifunctionality that he defines as multiple interactions between functionalities, which build resilience through increased robustness and redundancy within a community. Following his theory, sustainable and resilient communities develop similar multifunctional characteristics by, for example, considering a holistic set of capacities. This notion of "multifunctionality" (Wilson 2014; Wilson 2008) can be a particularly powerful theoretical concept in the community disaster risk literature for assessing benchmark capacities and their interactions in forward-looking standardized resilience measurement approaches (Keating et al. 2016; Mayunga 2007). For understanding and measuring community flood resilience, we adopt this "multifunctionality" approach and argue that specific systems or processes benefit from having welldeveloped human, financial, natural, social, and physical capitals within community boundaries - a concept inherent in the theoretical foundation of FRMC framework (Keating et al. 2017).

Keating et al. (2016), building on an interdisciplinary approach to disaster resilience, developed a conceptual systems framework that seeks to disentangle the interactions between disaster risk, disaster risk management, and sustainable development. This paper and the FRMC framework follow the definition of disaster resilience developed in that work: "the ability of a system, community, or society to pursue its social, ecological, and economic development and growth objectives, while managing its disaster risk over time, in a mutually reinforcing way" (Keating et al. 2016, p. 80). Under this definition, disaster resilience is more than the capacity for effective disaster risk management (although this is an integral part of it); it is the overall capacity of a community to thrive in the face of disaster risk.

\section{Disaster resilience measurement}

Alongside the recognition of disaster resilience as a holistic concept, particularly in the community context, there has been increasing debate by both academics and practitioners about the importance of developing and operationalizing systematic metrics of disaster resilience. There is currently neither a mainstream procedure for determining what needs to be assessed nor a standardized framework for defining measurements and metrics. Many scholars emphasize in their reviews the diverse approaches for measuring disaster resilience (Asadzadeh et al. 2017; Cutter 2016; Frankenberger et al. 2014; Mayunga 2007; Schipper and Langston 2015; Sharifi 2016). The three most common approaches can be classified into tools, scorecards, and indices with common elements focusing on attributes (such as infrastructure) and capacities (such as social capital) (Cutter 2016).

Quantitative analyses of selected disaster resilience indicators have been performed at the household and country level (Chacowry et al. 2018; Cimellaro et al. 2010; Cutter et al. 2010; Fekete 2018; Keating and Handmer 2011). Resilience indicators at the community level are less well studied. Most of the studies in the literature examine only one or two communities, thus providing non-consistent evidence rather than generalizable insight into the characteristics of community disaster resilience (Frankenberger et al. 2013; Frazier et al. 2013; Joerin et al. 2012; Johnson et al. 2018; Spector et al. 2019; Twigg 2009).

Measurement of disaster resilience is inherently complex for two key reasons: (1) it is a latent construct realized only in the case of a disaster (Engle 2011); and (2) as discussed above, the community (pre-event) characteristics that influence this latent construct are determined by a complex set of holistic, interdependent, and difficult-to-quantify variables (Keating et al. 2017). The challenge of measuring disaster resilience lies in determining which community (pre-event) characteristics make up this complex latent construct and measuring them before an event occurs. Any construct or index that purports to measure the key (pre-event) characteristics of resilience must then be validated by looking at the post-disaster outcomes and impacts. However, before this validation between pre- and post-event indicators can take place, tests must be performed on the construct of the pre-shock capacities, specifically measurability and consistency.

A further reason for the inadequate number of empirical studies on disaster resilience at the community level is that collecting consistent data for a large number of communities - which is necessary for drawing generalized conclusions - is a resource-intensive task. Work at the community level is also challenging because of the need to engage with many different stakeholder groups both within the community (e.g., individuals, business or trade groups, education professionals, and local government), as well as the 
interactions beyond community boundaries (i.e., at the municipal, national, or even global level).

Another challenge for community-level studies of disaster resilience is that disaster risk reduction investment by donors and national governments focuses on short-term and direct impacts (often using cost-benefit analyses) and ignores local engagement instruments and participatory methods because of the limited learning potential during project implementation (Mechler 2016). Currently, this perspective of disaster risk management mostly ignores the dynamics of human, social, and environmental functions which leads to suboptimal and unsustainable solutions that may in fact increase disaster risk in the long term (Heine and Pinter 2012; Sendzimir et al. 2008). To systematically assess the multifunctionality of resilience capacities, it is essential to investigate more into the multiple co-benefits of community functions to manage disaster resilience at the community level.

The process of measuring community disaster resilience is a necessary first step in order to understand the key capacities that are effective for disaster resilience and the challenges in building them (Keating et al. 2017; Campbell et al. 2019). While the importance of disaster resilience and its link to sustainable development has been discussed conceptually, a comprehensive method for measuring disaster resilience is needed to benchmark, build, and track progress in order to improve its relationship. In the current absence of a validated disaster resilience measurement, this paper develops a typology of flood resilience and links it with community socioeconomic characteristics. Similar methods for indicatorbased measurements have been conducted to identify socioecological pattern for farmers in dryland (Kok et al. 2016), vulnerable coastal communities (Chang et al. 2018; Lam et al. 2016), and Engle and Lemos (2010) identified links between governance indicators and adaptive capacity. Such approaches can share knowledge, resources, and successful practices that are relevant to a particular community's circumstances (Chang et al. 2018).

\section{Study area and data collection}

Our data were collected on 88 sources of resilience (i.e., resilience indicators) using the FRMC framework and tool. The FRMC approach (both framework and tool) was developed by the Zurich Flood Resilience Alliance, a partnership of nongovernmental organizations (NGOs), humanitarian organizations, risk engineers, and researchers (FRMC 2013; Keating et al. 2017). It is based on a systems-thinking approach for capturing the full potential of communities and understanding local resilience characteristics at larger scales. Our dataset consists of baseline measurements of resilience capacity (the 88 sources of resilience) taken during normal/non-flood times, and as such measure pre-event "latent" resilience rather than performance during or after a flood.

The goals of the FRMC framework are to (1) help guide community development by NGOs and programs based on flood risk, (2) provide a platform for the empirical analysis of resilience using a standardized measurement, and (3) enhance the ability of practitioners to standardize and measure flood resilience over time and compare how flood resilience changes as a result of different capacities and interventions (Keating et al. 2017). The FRMC framework builds on the five capitals of the Sustainable Livelihoods Framework (DfID 1999) and the 4Rs of a resilient system (robustness, redundancy, resourcefulness, and rapidity) (Bruneau 2006) to holistically measure the sources of flood resilience.

The FRMC framework has been operationalized by an indicator-based approach comprising 88 sources of resilience; each "source" is an indicator measuring a discrete pre-event characteristic thought to contribute to community flood resilience. Each source is assigned to one of the five capitals: human, financial, social, natural, or physical, one of the 4Rs, and three other categorizations (Keating et al. 2017).

Figure 1 illustrates the way the FMRC framework and its corresponding web and mobile-based tool was operationalized by trained users in communities.

For each source of resilience, users choose one or more data collection methods (household survey, community discussion group, key informant interview, interest group discussion, and secondary source data) they will use to collect data to answer pre-defined questions related to that sources. A mixedmethod data collection approach is usually applied to increase data reliability and robustness, and data are triangulated where possible. These data inform users trained in the FRMC framework to assign a grade - between A (best practice for managing the risk) and D (significantly below a good standard, with the potential for imminent loss) — to each source of resilience (see Keating et al. (2017) for a detailed description of the FRMC framework and application process including a face and content validity check to test usability and practicability of the FRMC tool).

To capture the diverse, unique socio-economic characteristics of communities, the FRMC tool also collects data on their socio-economic and demographic characteristics as well as their flood experience, sampled at the household and community level. ${ }^{1}$ Among these variables, details considered such as the distribution of livelihood strategies, education rate, or rate of female-headed household. Some variables are collected according to the communities' national standards, such as the variables for income distribution. A detailed overview of FRMC tool sampling methods can be found in Keating et al. (2017). Campbell et al. (2019) show an overview of the socio-

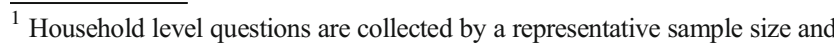
aggregated to the community level.
} 


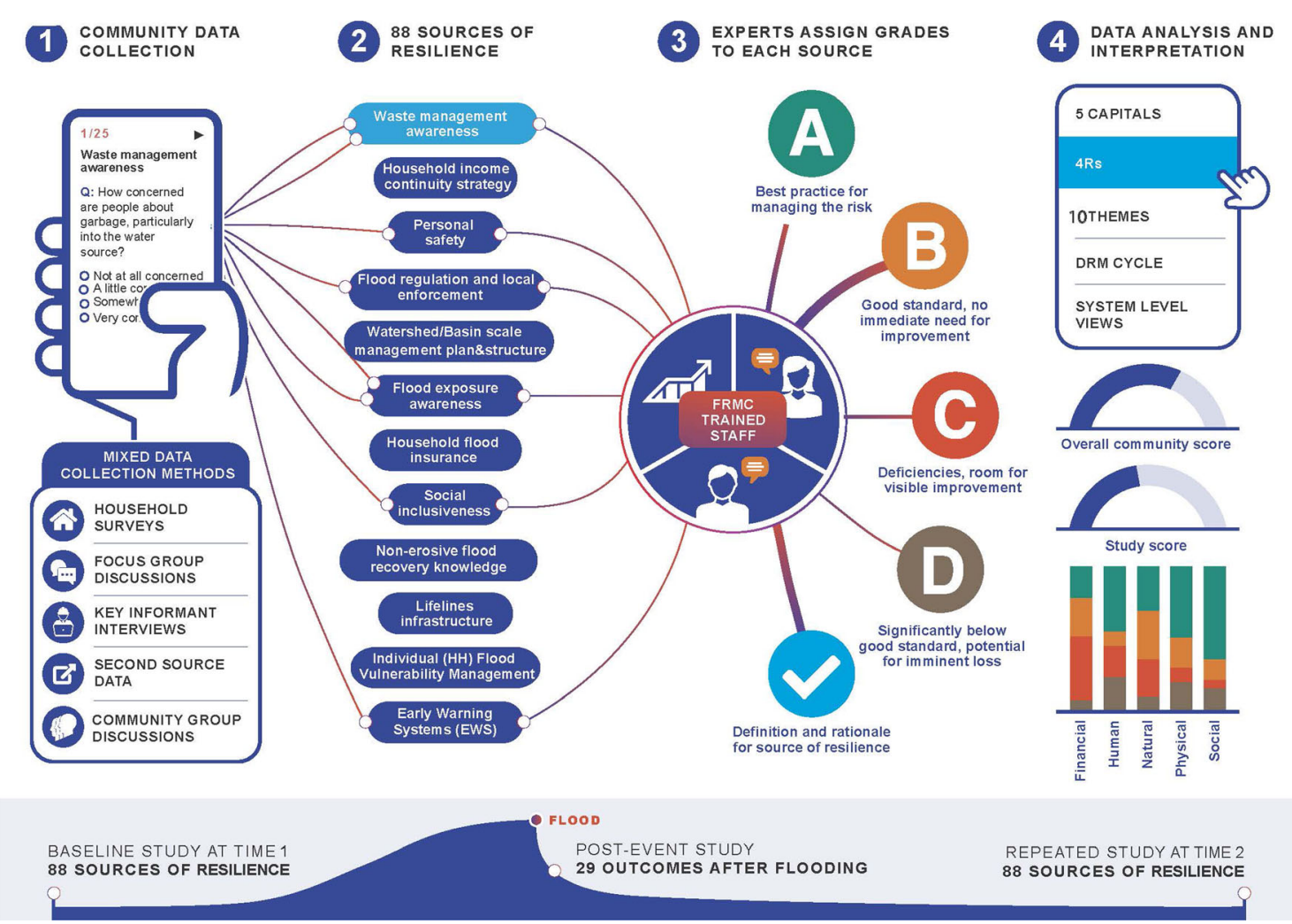

Fig. 1 Application process of the flood resilience measurement for communities. Details of the 88 sources are in supplementary material A. DRM, disaster risk management; FRMC, Flood Resilience Measurement for Communities; HH, household. Source: Authors' own

economic variables and the empirical insights of using the FRMC approach.

From 2015 to 2017 , members of the Zurich Flood Resilience Alliance applied the FRMC approach in 118 communities across nine countries to produce the first large-scale data set relating to baseline community flood resilience (see Fig. 1). More than 10,000 data points of source grades at the community level are currently included in the dataset. Our analysis is based on the grades and the communities' socioeconomic characteristics (for more details see supplementary material A1; a source example can be found in supplementary material A2). We test the relationship between these characteristics and a community's level of flood resilience capacity as measured by the FRMC approach.

Selection of communities was based on the (1) level of flood risk - high flood risk communities were selected, with risk level based on local knowledge of past flood events, (2) the availability of NGO support, and (3) the geographical and institutional accessibility of the communities. Many communities are relatively small in terms of population. This does not reduce the relevance of the data but reflects the representativeness of the regions in which the communities are located, being also a factor considered in the community selection process (see Keating et al. (2017) for a discussion about our applied community definition). Over the past 10 years, more than $80 \%$ of the 118 communities were impacted by at least one significant flood event, and catastrophic flood events occurred in more than one-third of the communities $(34 \%)^{2}{ }^{2}$ Therefore, we conclude that the communities included in our study are at high risk of future flood events and therefore the assessment of their flood resilience capacity will be an important factor for NGOs and humanitarian organizations in their programming decisions.

It is important to note that the FRMC approach is designed to be used in conjunction with various other participatory community development methods and tools such as vulnerability capacity assessment (VCA), transit walks, and participatory risk mapping exercises. The standardized and floodfocused nature of the FRMC approach means that it is only one input into a wider community development process, the other parts of which capture the nuanced localized context (see Keating et al. 2017 for further details). Feedback from the NGOs and humanitarian organizations using the FRMC in the 118 communities indicated that the software was userfriendly. Users particularly appreciated the mobile data collection and web-based application, which they reported to be superior to traditional paper-based methods (Zurich Flood Resilience Alliance internal report 2017).

\footnotetext{
$\overline{2}$ The FRMC trained practitioners assigned a label to past flood events according to the following definitions, which are based on the return period of the flood hazard: normal, 1-2-year event; significant, 2-10-year event; exceptional, 10-100-year event; catastrophic, $100+$ year event. We found that in many cases, households interpreted this question to be about the severity of the flood impacts. The data therefore represent fully realized risk (considering hazard, exposure, and vulnerability) rather than the hazard in isolation.
} 


\section{Method for analyzing community flood resilience clusters}

The 88 sources of resilience were designed around the five capitals approach and it therefore makes sense to aggregate them accordingly. For simplicity, and as is typically done in such analyses, the A-D ordinal scale of the source grades is treated as continuous (i.e., $D=0, C=33, B=66$, and $A=$ 100). This is an acceptable practice because we focus our analysis on the aggregate level (taking the average over all selected sources), which usually serves as a good approximation of a continuous scale - being also a requirement for the following statistical analysis (Backhaus et al. 2016).

\section{Measurability and consistency of indicators}

We conduct multivariate statistical analyses to test the reliability of the FRMC data in order to determine whether the FRMC framework is able to (a) define its own key underlying dimensions and (b) consistently measure the sources of resilience. Namely, we estimate measurability and consistency of our baseline indicators to aid interpretational power to the benchmark tests.

First, we test the internal consistency of the five capitals and the corresponding 88 sources of resilience by applying Cronbach's alpha (Backhaus et al. 2016; Field 2009). Second, we examine the underlying theoretical models of the five capitals on the basis of the assigned sources of resilience. By tackling this question, we also gain information about the underlying structure of the FRMC framework and its measurability. A principal component analysis (PCA) with a one-component model using the Kaiser criterion (eigenvalues $>1$ ) is conducted for the five capitals. We then perform a PCA using the varimax rotation to aid interpretability of the component matrix (Kaiser 1970). The methodology of the PCA follows standard practice, as set out in Nardo et al. (2005). By performing this varimax rotation PCA, we identify the main underlying dimensions of five capitals for measuring flood resilience (McNeil et al. 2015). Furthermore, we test the potential of reducing the number of sources ${ }^{3}$ (for more details on statistical requirements and the results of the PCA with adjusted Cronbach's alpha, see supplementary material B1).

\section{Cluster analysis and correlation analysis}

In order to develop a typology of community flood resilience, we investigate the relationship between socio-economic community

\footnotetext{
${ }^{3}$ While we identified 15 sources of resilience (see the supplementary material B1 Table 1) that can increase the explained variance and Cronbach's alpha if deleted, owing to the uncertainty as to which sources would actually be important during a specific flood event, we retained all sources.
}

characteristics and flood resilience as measured by the FRMC approach. To do this, we carry out a cluster analysis to identify community cluster profiles with substantial similarity in source grades, as grouped by the five capitals. Specifically, we conduct a hierarchical cluster analysis based on Ward's method with a squared Euclidean distance function (see Backhaus et al. 2016 for a comparison of schemes), whereby we assume clusters are homogenous within and heterogeneous between each other.

The relationship between community cluster profiles and socio-economic characteristics are then analyzed to further describe the community typology. To do this, the most relevant socio-economic variables for characterizing the cluster profiles are selected by qualitative expert judgment (Keating et al. 2017) and then formally tested by non-parametric statistical tests. We use the Kruskal-Wallis test to explore the statistical cluster differences for each socio-economic variable because the data does not meet the requirements for parametric tests (e.g., analysis of variance). We anticipate that any socio-economic or flood-related variable is unlikely to explain the total variance of the flood resilience cluster profiles, but a good overlay of a set of these variables may explain some portion of the variance in flood resilience pattern. Those socio-economic variables that perform well in the statistical analysis are then used to qualitatively evaluate the socio-economic state of the cluster profiles (see supplementary material $\mathrm{A} 1$ for a list of variables and more details on the results in supplementary material B 2).

Next, we perform a bivariate correlation analysis to define the correlative relationships between the five capitals. A higher correlation value indicates higher interactions between the capitals. As we cannot predict causation between the five capitals, we assume - as Wilson (2010) suggests - interdependencies among them. Following from this, when interpreting the correlation analysis, it is critical to note that high correlation means that if only some community capacities work well, it is more likely that serious challenges will arise during a flood; as soon as one function fails, the whole network fails. In this sense, a community with similar results for the five capitals but with highly correlated values is less likely to fail than a similar community with lower correlated values (for more details on the results see supplementary material B 3 ).

In sum, performing the cluster analysis, exploratory data analysis, and bivariate correlation analysis, we sought to empirically identify strong and weak flood resilience cluster profiles and then associate them with socio-economic variables in order to define a flood resilience typology of communities. This process allows us to identify for each cluster profile a unique relationship between a community's flood resilience level and its socio-economic characteristics. The relationships were investigated by analyzing the interactions between the five capitals. The results of these analyses provided deep insight into the multiple functionalities of communities in terms of human, financial, natural, social, and physical capitals. 
Table 1 Cronbach's alpha coefficient for the five capitals in the study

\begin{tabular}{llc}
\hline Capital & Cronbach's alpha & No. resilience sources \\
\hline Human & 0.82 & 16 \\
Financial & 0.86 & 17 \\
Natural & 0.81 & 6 \\
Social & 0.93 & 33 \\
Physical & 0.83 & 16 \\
\hline
\end{tabular}

\section{Results}

\section{Measurability and consistency of indicators}

The internal consistency test results indicate high internal consistency for all five capitals (see Table 1). For all capitals, Cronbach's alpha returns a value greater than 0.8 , which is generally seen as an acceptable value for internal consistency (Field 2009). Therefore, we conclude that the sources of resilience are assigned consistently to their respective capitals, and that the measures of the five capitals can be aggregated (with equal weightings).

The results show an explained variance of between 30 and $50 \%$, which is adequate for such a complex underlying structural model (Field 2009). The one-component PCA with all 88 sources of resilience explains $24 \%$ of the variance. By performing the varimax rotation PCA, we identified an underlying structure of 18 subcomponents for measuring flood resilience. Like the five capitals, the internal consistency of the 18 sub-capitals is good or very good, meaning that they are measured consistently. As expected with a dimension reduction method, the explained variance increased significantly for all capitals: the total explained variance was about $62 \%$ for human capital, $68 \%$ for financial capital, $64 \%$ for natural capital, $68 \%$ for social capital, and $61 \%$ for physical capital (for more details on the results of the PCA with adjusted Cronbach's alpha, see Table 1 in the supplementary material B1).

Building on insights regarding the underlying structure of each capital, we examined the underlying capacity indicators (sources of resilience) for each of the subcomponents in order to identify the latent construct of each subcomponent. We found that financial capital has four subcomponents, which we defined according to the content of the sources in each subcomponent: financial budget management, flood-related financial management decisions, financial safety nets, and financial market access. Human capital consists of four subcomponents: health and education, vulnerability awareness, hazard awareness, and exposure awareness. For natural capital, the underlying structure is complex, and no structure is identified which may be reflected by the lower number of sources and a less cohesive definition of this capital. However, a focus on environmental community perception emerged from the explained variance of the natural capital sources after the varimax rotation. Physical capital consists of three subcomponents identified as: flood coping infrastructure, basic needs infrastructure, and emergency response infrastructure. For social capital, six subcomponents were identified: flood resilience governance, institutional capital, flood risk perception, community engagement in flood resilience planning, contingency planning, and security.

Overall, the results of the multivariate analysis show that even without the source reduction, the sources of resilience can be used for the five capitals in the FRMC framework, which means a sufficient level of measurability and consistency exists and we can continue using other analytical methods (e.g., cluster analysis and bivariate correlation analysis).

\section{Identification of community cluster types}

Turning now to the cluster analysis, Fig. 2 shows the four cluster profiles identified, which each contain at least $12 \%$ of the communities. ${ }^{4} \mathrm{We}$ found relatively low levels of flood resilience across capitals, in cluster 1 and in particular, the flood resilience capital scores are all lower than those in all other clusters. In contrast, cluster 4 has the highest scores across all five capitals (except for human capital which is equal to cluster 3), while scores for clusters 2 and 3 fall in between those of clusters 1 and 4. Looking deeper into the cluster analysis results, we see that clusters 2 and 4 show low variation between capitals within the cluster profiles (homogeneous capital scores) with a variance $\left(\sigma^{2}\right)$ of 33.2 and 37.5 respectively, while clusters $1\left(\sigma^{2}=96.2\right)$ and $3\left(\sigma^{2}=239\right)$ have a high variance (heterogeneous capital scores). Cluster 1 shows some variance and low scores for financial, natural, and social capital. Cluster 3 has particularly high variance, being very weak in natural capital and strong in human and physical capital.

We overlaid the distinct community cluster profiles with the socio-economic characteristics to explore whether flood resilience cluster profiles have similar development profiles. The most significant socio-economic characteristics are shown in Fig. 3 as a distribution plot. Based on the analysis of pairwise comparison (post-hoc tests), we found that for all socio-economic characteristics, at least one cluster is significantly different from the others (see supplementary material B2 for more details).

In cluster 1 (red area in Fig. 3), households in communities from Afghanistan Haiti Indonesia and Timor-Leste tend to be significantly less educated, and the cluster has a significantly higher proportion of low-income households. The correlation coefficient $(0.44, p>0.05)$ between flood exposure and low-

\footnotetext{
${ }^{4}$ Note: The 118 communities are distributed into four clusters. Cluster 1 includes 29 communities, cluster 2 has 51 communities, cluster 3 consists of 24 communities, and cluster 4 builds on 14 communities.
} 


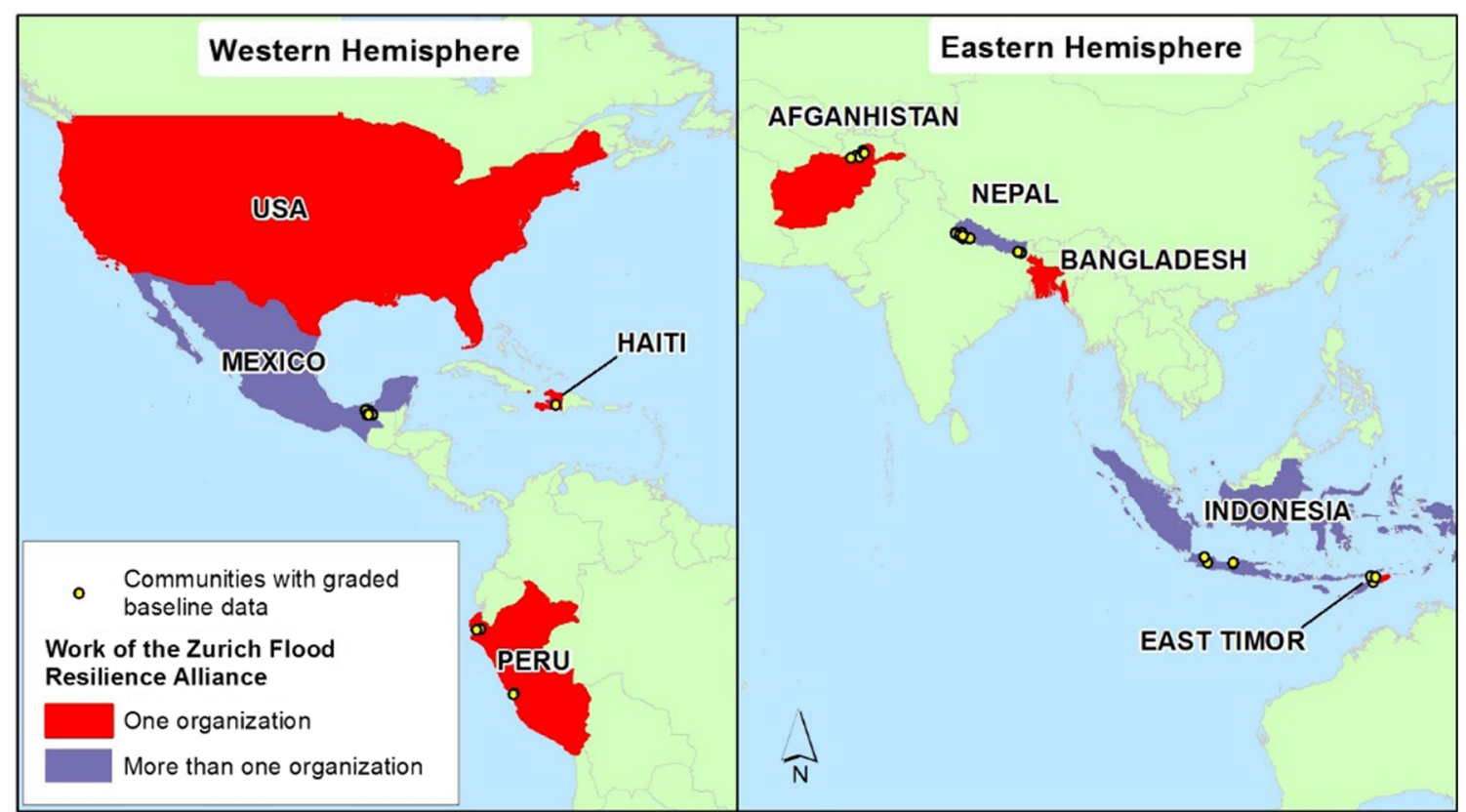

Fig. 2 Map of the countries where our Partners are working. (Source: Campbell et al. 2019)

income class also emphasizes the relationship between lowincome and significant flood events. Further, the cluster is characterized by rural settlements $(62 \%)$. Hence, the typology for cluster 1 is "very poor, struggling rural communities with significant flood risk."

Cluster 2 (green area in Fig. 3) is the largest cluster group with 51 communities from Bangladesh, Indonesia, Mexico, Nepal, and Peru. This cluster has the lowest variance in capital scores. The development stage of this cluster profile is relatively rural (64\%), and it has a higher proportion of educated households and flood exposure than cluster 1. Interestingly, the largest overlap in socio-economic variables of this cluster is found with cluster 4 , which has also a similar capital variance (see supplementary material B2 for the pairwise comparison of cluster profiles). The typology for cluster 2 is "poor but thriving rural communities with highly significant flood risk.",
In cluster 3 (blue area in Fig. 3), households tend to be in the middle-income group (according to their own country's standards from Bangladesh, Indonesia and Mexico), are in an urban or a peri-urban setting, and depend more on employment in the manufacturing and service sectors than in the agriculture sector for their livelihood strategies. These characteristics support the finding that in these communities the flood resilience level of natural capital is rather disconnected (uncorrelated) from the other capitals. In the past 10 years, flood exposure was relatively low. Looking across all socioeconomic variables, cluster 3 has the most significant differences across all socio-economic variables (see supplementary material B2 for the pairwise comparison of cluster profiles). The typology for cluster 3 is "middle-income peri-urban and urban communities with less frequent flood risk."

Communities in cluster 4 (purple area in Fig. 3) have the highest level of flood resilience capacity across all capitals.
Fig. 3 Resilience capital scores for the four community cluster types. The cluster analysis was performed using the capital scores of 118 communities

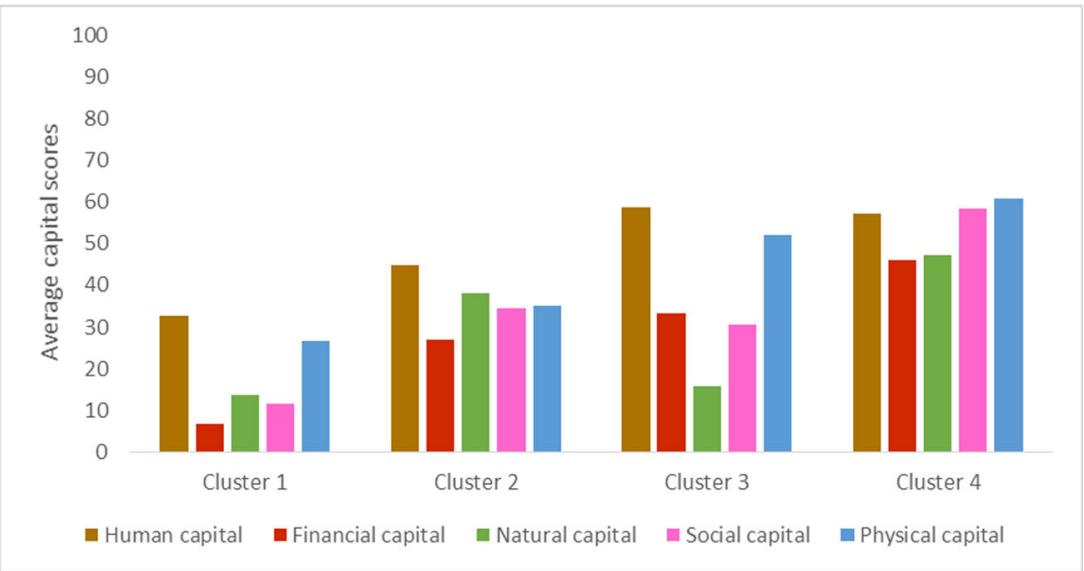


The profile of the cluster can be described as a mix of settlement types (rural, peri-urban, and urban), and household groups (low, middle, and high income) are relatively equally distributed, with the largest share of households belonging to the middle-income group from countries such as Bangladesh, Indonesia, Mexico, Nepal and the USA). Cluster 4 has some parallels to cluster 2 in that education rate and flood exposure are similar in the two clusters. We also found that flood exposure and the proportion of income groups in this cluster are correlated (correlation coefficients above $0.65, p>0.05$ ). The typology for cluster 4 is "middle-income mixed type communities with more frequent flood risk."

From the bivariate correlation analysis, we found high correlations between all capitals (correlation coefficients above $0.64, p>0.05$ ) except for natural capital. The highest positive correlation coefficients we found were between social and financial capital $(0.77, p>0.05)$ and financial and physical capital $(0.72, p>0.05)$. The lowest positive correlation coefficients were between natural capital and all other capitals (between 0.2 and 0.5), indicating that natural capital is the most independent capital type.

Unsurprisingly, the interdependencies of capitals varied when we performed the clustered bivariate correlation analysis. Figure 4 shows the results of the clustered bivariate correlation analyses controlled by four clusters with the most significant and highest results. We found that cluster 1 has a negative correlation between natural and social capital $(-0.4)$ and a positive correlation between physical and social capital (0.38), both with a significance level of 0.05 . All other correlations are lower and not significant. Cluster 2 shows significant positive correlations for financial, physical, and social capital. Interestingly, human and natural capital may not be considered to be closely related to each other, but each is positively correlated with all other capitals $(>0.35)$. In cluster 3 , we find highly significant negative interdependencies between natural and physical capital $(-0.58)$. The second highest correlation is between human and social capital, followed by physical and social capital (all highly significantly correlated). In cluster 4, financial capital is highly interlinked with all other capitals. The highest dependency identified is between financial and natural capital $(0.84)$, followed by financial and human capital (0.77), and financial and social capital (0.7).

\section{Discussion: a typology of community flood resilience}

On the basis of the results of the cluster analysis of flood resilience levels, the Kruskal-Wallis test for differences in
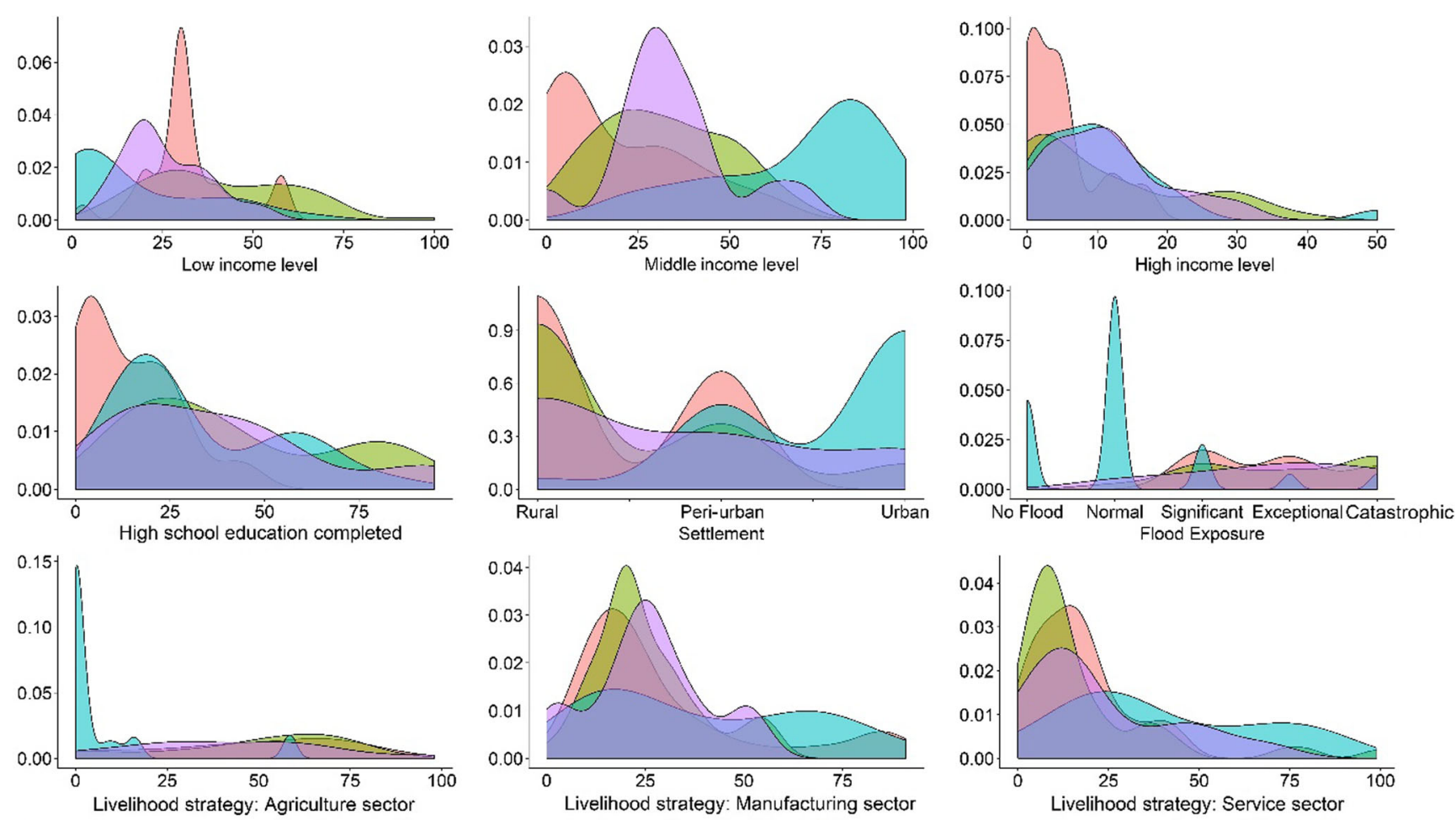

Cluster 1: 'very poor, struggling rural communities with significant flood risk'

$\square$ Cluster 3: 'middle-income peri-urban and urban communities with less frequent flood risk'

Cluster 2: 'poor but thriving rural communities with highly significant flood risk'

$\square$ Cluster 4: 'middle-income mixed type communities with more frequent flood risk'

Fig. 4 Defining the community types by the distribution of socio-economic variables. The larger the area that appears higher toward the right-hand side of the $x$-axis, the more relevant is the socio-economic variable for the cluster 
socio-economic characteristics and the clustered bivariate correlation analysis for multiple capital interdependencies, we developed a typology of community flood resilience. We identified four cluster types with different socio-economic development stages and different capital interactions (see Fig. 4, for more details about the statistical results we refer to supplementary material B3).

Cluster 1 has the weakest flood resilience capacity level of all cluster types. It also has weak interconnections between capitals, with some being negatively correlated. The communities in this cluster are relatively poor and struggle the most to cope with and recover from the impacts of floods. Barriers that hinder development, such as low income, poor education, and the impacts of floods, are most likely significant drivers of the low flood resilience scores. These and other communities with a similar socio-economic profile could focus their scarce resources on leveraging their relatively higher human capital capacities to strengthen the financial and social capitals. This could help increase their flood resilience and have significant co-benefits in terms of their development.

Poor but thriving rural communities with highly significant flood risk (cluster 2) have a significantly higher flood resilience capacity level than cluster 1 communities. In addition, the clustered bivariate correlation analysis shows positive and higher values, indicating that community functions are better integrated than in cluster 1 . While the communities with this cluster profile show low socio-economic status, their flood resilience level is also low and closely linked to the socioeconomic status. Multiple interactions between capitals exist, but some links could be enhanced (e.g., awareness (human capital) of the role of natural capital in flood resilience).

Urban moderately resilient communities as identified by cluster 3 (middle-income peri-urban and urban communities with less frequent flood risk). Communities in this cluster have unequal capital distribution: natural capital is very low compared with physical capital. The correlations between these two are also negative. Given the difficulty measuring natural capital, the fact that there is a negative correlation between natural and physical capital shows that there is often a trade-off between the natural and built environment that potentially needs additional considerations. For urban settlements, the substitution effect between natural and physical capitals is well known owing to the amount and density of built infrastructure. However, a high resilience level in one capital does not necessarily equate to a high level of flood resilience because the substitution effect may also increase risks: this is sometimes known as the levee effect (Collenteur et al. 2015; Heine and Pinter 2012; Sendzimir et al. 2008). The cluster 3 type thus describes communities that have moderate resilient capacity, with some well-developed interactions, but that may be vulnerable in the longer term due to some disconnect with their natural capacities and the threat of hidden disaster risks.

A higher level of flood resilient capacity is likely to be found in cluster 4 communities (middle-income mixed type

\begin{tabular}{|c|c|c|c|c|}
\hline uster typology & $\begin{array}{l}\text { Very poor, struggling } \\
\text { rural communities with } \\
\text { significant flood risk }\end{array}$ & $\begin{array}{l}\text { Poor but thriving rural } \\
\text { communitieswith highly } \\
\text { significant flood risk }\end{array}$ & $\begin{array}{l}\text { Middle-income peri- } \\
\text { urban and urban } \\
\text { communities with less } \\
\text { frequent flood risk }\end{array}$ & $\begin{array}{l}\text { Middle-income mixed } \\
\text { type communities with } \\
\text { more frequent flood risk }\end{array}$ \\
\hline
\end{tabular}

\section{Multifunctionality}
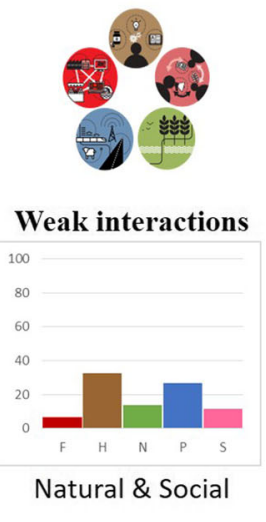

Highest
correlation
$2^{\text {nd }}$ highest
correlation
$3^{\text {rd }}$ highest
correlation

\section{Cluster characteristics}

correlation $\left(-0.4^{*}\right)$

Physical \& Social

$\left(0.38^{*}\right)$

No significant correlation
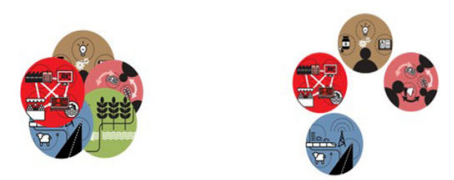

Moderate interactions Moderate interactions

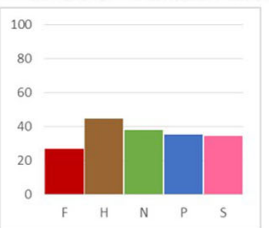

Financial \& Physical

$(0.57 * *)$

Social \& Human

$\left(0.5^{* *}\right)$

Financial \& Social

$(0.36 * *)$

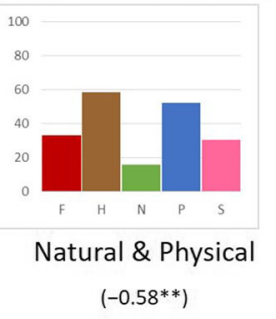

Social \& Human

$\left(0.57^{* *}\right)$

Physical \& Social

$\left(0.54^{* *}\right)$

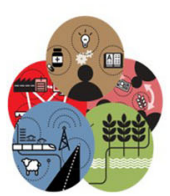

Strong interactions

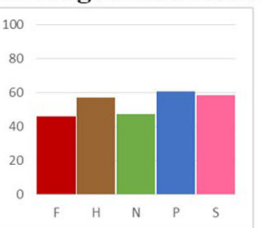

Financial \& Natural

$\left(0.84^{* *}\right)$

Financial \& Human

$\left(0.77^{* *}\right)$

Financial \& Social

$\left(0.7^{* *}\right)$

Fig. 5 Cluster types, cluster characteristics, and bivariate correlation analysis showing highly significant capitals both overall and between clusters. Pearson correlation analysis (two-tailed test): **correlation significant at the 0.01 level; *correlation significant at the 0.05 level 
communities with more frequent flood risk). These communities have the highest flood resilience level and high interdependencies between capitals. Causation between higher capital levels and higher correlations is not stated, but an intuitive interpretation is that they develop interactively because all capitals are required for integrated community development. Communities with these characteristics are more likely to cope with the negative impacts of disasters such as flooding. The presence of financial capital is identified as particularly important for building flood resilience capacity and for enhancing multiple benefits in other capitals, as well as in general community development. The dominance of medium income in these communities together with a well-balanced income distribution across households might be contributing factors to the importance of financial capital. Both of these socio-economic characteristics are key requirements for building resilience (Chaskin 2008), and they are especially interesting in examples of best practice to investigate the relationship between flood resilience and prevailing development conditions (Fig. 5).

\section{Conclusions and outlook}

The analysis of community pre-event characteristics in our dataset achieved through the implementation of the FRMC approach provides a systematic way to begin developing a typology of community flood resilience. The findings of the analysis highlight important aspects of community flood resilience and its interactions with socio-economic development. We have considered our findings in light of similar work and the theoretical framework of multifunctionality, which suggests that communities with a well-balanced capital profile are more resilient (Wilson 2010).

We first showed the measurability and consistency of measuring the sources of flood resilience and the applicability of the FRMC framework across scales and community contexts, an aspect that is highly relevant but often neglected in similar studies. Our analysis found that the FRMC framework is a well-constructed and internally consistent framework for measuring flood resilience. The most critical subcomponents represent 18 dimensions associated with five capitals (human, financial, social, natural, and physical). The interpretation of the subcomponents can be understood as the latent constructs of flood resilience to adequately define pre-event metrics for community flood resilience assessments. Capturing these dimensions is critical for any community flood resilience metric. For example, when measuring flood resilience with a physical capital lens, at least three dimensions (basic needs infrastructure, flood coping infrastructure, and emergency response infrastructure) are pivotal to consider.

Secondly, we developed a typology of communities to better determine the relationships between flood resilience capacity across the five capitals and community development represented by a set of socio-economic variables. The cluster profiles showed that flood resilience capacity can be found in poor rural communities as well as middle-income urban communities, which points to significant potential for targeted enhancement of flood resilience when supported by this standardized measure. The typology also found some nuance among the interactions between the capitals, where in some cases the capitals can act as substitutes and other times as complements.

Third and most importantly, we drew on the systemsanalytical concept of multifunctionality and, in line with other studies, we found that communities with higher interactions between their capitals also tended to have higher flood resilience levels. The bivariate correlation analysis of the five capitals showed a strong interplay between socio-economic characteristics, reinforcing the fact that the FRMC framework has been designed to facilitate the building of flood resilience across all community functions in a holistic and integrative manner. While the sources of resilience are a priori defined to measure resilience capacity systematically and holistically, which has been proven by our analysis, we also note that some dimensions of flood resilience cannot be fully captured in an empirical data collection process. Furthermore, we have not yet tested these sources of resilience against post-flood measures of the actual outcomes of resilience (e.g., less loss, quicker, and better recovery). This step is critical for validating a measure of flood resilience capacity.

For the four cluster profiles of the typology, we found community flood resilience levels to be clustered according to uniformly low or high capital levels, as shown in cluster 1 (very poor, struggling rural communities with significant flood risk), cluster 2 (poor but thriving rural communities with highly significant flood risk), and cluster 4 (middle-income mixed type communities with more frequent flood risk). It is interesting to note that our findings for cluster 3 (middle-income peri-urban and urban communities with less frequent flood risk), which has urban characteristics and strong nonagriculture sectors, do not fully match with the multifunctionality concept of Wilson (2014), who specifically addresses resilience in rural communities. For cluster 3, we found that urban communities' capacities have different interactions, with negative capital correlations and a greater potential for substituting natural functions with human-built constructions. This can allow the communities to increase their flexibility to adapt and to pursue social, ecological, and economic development over time.

In general, our typology of community flood resilience lays out the diversity of community types that need investment in enhancing their flood resilience, while considering the community-specific constraints in terms of human, financial, natural, physical, and social capitals. However, identifying efficient interventions and feasible opportunities for flood 
resilience investments can be a massive challenge. Often this requires prioritization across community boundaries and across scales. Making these decisions is complex and requires a system-based approach. This paper found that the measurement of community flood resilience capacity can structure and support this process and aid in decision-making informed by a holistic picture of community flood resilience; the typology of community flood resilience supports this. By first measuring a community's flood resilience capacity and then identifying its community cluster, stakeholders can engage in discussions about the feasible ways to strengthen weaker resilience capacities, while understanding the multiple benefits related to stronger capitals. Potentially, it can also operate to advocate for community needs at regional or national policies, by bringing data driven evidence for proposals. It can also aid in sharing experiences in a structured way between local NGOs and humanitarian organizations and provide support for decisions related to building flood resilience in communities. Finally, the typology of community flood resilience marks a step forward in improving methodologies and in the classification of flood resilience for practitioners and decision-makers to use in evaluating post disaster situations.

For national or global organizations and donors, the typology of flood resilience provides a general structure to inform national and international disaster risk management programs with context-specific information regarding how resilience and development need to be considered for communitybased investment strategies. In particular, best practice examples for community interventions can be shared by communities within cluster profiles. National programs can also use this typology to identify communities with similar profiles in order to engage with them in a more context-specific manner.

In the long-term effort, measuring resilience seems to be a promising way forward toward more evidence-based decision support; however, for more detailed policy recommendation national authority involvement should be more committed to the data collection process. Since, measuring resilience needs time and resources but the process itself can also increase capacity in the community. The typology of flood resilience shows evidence how best-practice examples should be shared across communities and countries. This paper shows that capitals are interdependent, and therefore older views of development that do not account for this interdependency may waste valuable investment dollars investing in areas that have relatively lower rates of return in terms of reducing risk and increasing development.

Regarding future directions, we plan to test how interactions of capitals can be fostered by socio-economic development and flood resilience building interventions. One hypothesis is that efforts to increase human capital depend to some extent on the availability of financial capital. However, such efforts can also have adverse effects because financial capital accumulation depends on human capital. It is also likely that both capitals create multiple benefits for other capitals. This implies that if financial capital increases - for example, by interventions to enhance livelihood strategies or financial security-some of the effects are likely to flow into and increase co-effects for other capitals such as physical capital.

Acknowledgments We acknowledge the financial support of the $\mathrm{Z}$ Zurich Foundation and the immense work by all partners of the Zurich Flood Resilience Alliance. We are specifically grateful for all contributions from NGO partners.

Funding Information Open access funding provided by International Institute for Applied Systems Analysis (IIASA).

Open Access This article is licensed under a Creative Commons Attribution 4.0 International License, which permits use, sharing, adaptation, distribution and reproduction in any medium or format, as long as you give appropriate credit to the original author(s) and the source, provide a link to the Creative Commons licence, and indicate if changes were made. The images or other third party material in this article are included in the article's Creative Commons licence, unless indicated otherwise in a credit line to the material. If material is not included in the article's Creative Commons licence and your intended use is not permitted by statutory regulation or exceeds the permitted use, you will need to obtain permission directly from the copyright holder. To view a copy of this licence, visit http://creativecommons.org/licenses/by/4.0/.

\section{References}

Adger WN (2000) Social and ecological resilience: are they related? Prog Hum Geogr 24:347-364. https://doi.org/10.1191/ 030913200701540465

Adger WN, Hughes TP, Folke C, Carpenter SR, Rockström J (2005) Social-ecological resilience to coastal disasters. Science (80- ) 309: 1036-1039. https://doi.org/10.1126/science. 1112122

Asadzadeh A, Kötter T, Salehi P, Birkmann J (2017) Operationalizing a concept: the systematic review of composite indicator building for measuring community disaster resilience. Int J Disaster Risk Reduct. https://doi.org/10.1016/j.ijdrr.2017.09.015

Backhaus K, Erichson B, Plinke W, Weiber R, Schuchard-Ficher C, Weiber R (2016) Multivariate analysemethoden: eine anwendungsorientierte einführung. Springer Gabler SpringerVerlag, Berlin. https://doi.org/10.1007/3-540-29932-7

Béné C, Wood RG, Newsham A, Davies M (2012) Resilience: new utopia or new tyranny? Reflection about the potentials and limits of the concept of resilience in relation to vulnerability reduction programmes IDS Work Pap https://doi.org/10.1111/j.2040-0209. 2012.00405.x

Berkes F, Folke C (1998) Linking social and ecological systems: management practices and social mechanisms for building resilience. Cambridge University Pres, New York

Berkes F, Ross H (2013) Community resilience: toward an integrated approach. Soc Nat Resour 26:5-20. https://doi.org/10.1080/ 08941920.2012 .736605

Bruneau M (2006) Enhancing the resilience of communities against extreme events from an earthquake engineering perspective. J Secur Educ 1:159-167. https://doi.org/10.1300/J460v01n04 14 
Campbell KA, Laurien F, Czajkowski J, Keating A, Hochrainer-Stigler S, Montgomery M (2019) First insights from the flood resilience measurement tool: a large-scale community flood resilience analysis. Int. J. Disaster Risk Reduct 40:101257. https://doi.org/10.1016/j.ijdrr. 2019.101257

Chacowry A, McEwen LJ, Lynch K (2018) Recovery and resilience of communities in flood risk zones in a small island developing state: a case study from a suburban settlement of Port Louis, Mauritius. Int J Disaster Risk Reduct 28:826-838. https://doi.org/10.1016/j.ijdrr. 2018.03.019

Chang SE, Yip JZK, Conger T, Oulahen G, Marteleira M (2018) Community vulnerability to coastal hazards: developing a typology for disaster risk reduction. Appl Geogr 91:81-88. https://doi.org/10. 1016/j.apgeog.2017.12.017

Chaskin RJ (2008) Resilience, community, and resilient communities: conditioning contexts and collective action. Child Care Pract 14: 65-74. https://doi.org/10.1080/13575270701733724

Cimellaro GP, Reinhorn AM, Bruneau M (2010) Framework for analytical quantification of disaster resilience. Eng Struct 32:3639-3649. https://doi.org/10.1016/j.engstruct.2010.08.008

Collenteur RA, de Moel H, Jongman B, Di Baldassarre G (2015) The failed-levee effect: do societies learn from flood disasters. Nat Hazards 76:373-388. https://doi.org/10.1007/s11069-014-1496-6

Constas M, Frankenberger T, Hoddinott J (2014) Resilience measurement principles: toward an agenda for measurement design. In: Resilience measurement, technical series no. 1. Food security information network, Rome, Rome

CRED (2018) Natural disaster 2017. CRED, Brussels 2018 EM-DAT file dated 02/07/2018

Cutter SL (2016) The landscape of disaster resilience indicators in the USA. Nat Hazards 80:741-758. https://doi.org/10.1007/s11069015-1993-2

Cutter SL, Barnes L, Berry M, Burton C, Evans E, Tate E, Webb J (2008) A place-based model for understanding community resilience to natural disasters. Glob Environ Chang 18:598-606. https://doi.org/ 10.1016/j.gloenvcha.2008.07.013

Cutter SL, Burton CG, Emrich CT (2010) Disaster resilience indicators for benchmarking baseline conditions. J Homel Secur Emerg Manag 7:1-22. https://doi.org/10.2202/1547-7355.1732

Cutter SL, Ash KD, Emrich CT (2014) The geographies of community disaster resilience. Glob Environ Chang 29:65-77. https://doi.org/ 10.1016/J.GLOENVCHA.2014.08.005

Davoudi S, Shaw K, Haider LJ, Quinlan AE, Peterson GD, Wilkinson C, Fünfgeld H, McEvoy D, Porter L, Davoudi S (2012) Resilience: a bridging concept or a dead end? "Reframing" resilience: challenges for planning theory and practice interacting traps: resilience assessment of a pasture management system in northern Afghanistan urban resilience: what does it mean in Planni. Plan Theory Pract 13: 299-333. https://doi.org/10.1080/14649357.2012.677124

Deneulin S, Shahani L (2009) An introduction to the human development and capability approach: freedom and agency, human development and capability association. Earthscan and IDRC, London

DfID (1999) Sustainable livelihoods guidance sheets Introduction: overview, sustainable livelihoods guidance sheets. https://doi.org/10. $1002 / \mathrm{smj}$

Engle NL, Lemos MC (2010) Unpacking governance: building adaptive capacity to climate change of river basins in Brazil. Glob Environ Chang 20:4-13. https://doi.org/10.1016/j.gloenvcha.2009.07.001

Engle, N.L., 2011. Adaptive capacity and its assessment. Glob. Environ. Chang. 21, 647-656. https://doi.org/10.1016/J.GLOENVCHA. Accessed 1.19.11

Fekete A (2018) Societal resilience indicator assessment using demographic and infrastructure data at the case of Germany in context to multiple disaster risks. Int. J. Disaster Risk Reduct 31:203-211. https://doi.org/10.1016/j.jidrr.2018.05.004
Field A (2009) Discovering statistics using SPSS. Sage Publication, New York. https://doi.org/10.1234/12345678

Folke C, Carpenter S, Elmqvist T, Gunderson L, Holling CS, Walker B (2002) Resilience and sustainable development: building adaptive capacity in a world of transformations. AMBIO A J Hum Environ 31:437-440. https://doi.org/10.1579/0044-7447-31.5.437

Frankenberger T, Mueller M, Spangler T, Alexander S (2013) Community resilience: conceptual framework and measurement. Westat, Rockville

Frankenberger T, Constas MA, Nelson S, Starr L (2014) Resilience programming among nongovernmental organizations: lessons for policymakers, resilience for food and nutrition security. IFPRI Food Policy Report, Washington, D.C. https://doi.org/10.2499/ 9780896295650

Frazier TG, Thompson CM, Dezzani RJ, Butsick D (2013) Spatial and temporal quantification of resilience at the community scale. Appl Geogr 42:95-107. https://doi.org/10.1016/j.apgeog.2013.05.004

FRMC (2013) Flood resilience measurement for communities [WWW document]. https://floodresilience.net/frmc. Accessed 12.5.18

Hallegatte S (2014) Economic resilience: definition and measurement. World Bank Gr Policy Res Work Pap WPS 6852

Heine RA, Pinter N (2012) Levee effects upon flood levels: an empirical assessment. Hydrol Process 26:3225-3240. https://doi.org/10.1002/ hyp. 8261

Holling CS (1973) Resilience and stability of ecological systems. Annu Rev Ecol Syst 4:1-23. https://doi.org/10.1146/annurev.es.04. 110173.000245

Holling CS (1996) Engineering resilience versus ecological resilience Eng within Ecol constraints 31, 32

Joerin J, Shaw R, Takeuchi Y, Krishnamurthy R (2012) Assessing community resilience to climate-related disasters in Chennai, India. Int $\mathrm{J}$ Disaster Risk Reduct 1:44-54. https://doi.org/10.1016/j.ijdrr.2012. 05.006

Johnson RM, Edwards E, Gardner JS, Diduck AP (2018) Community vulnerability and resilience in disaster risk reduction: an example from Phojal Nalla, Himachal Pradesh, India. Reg Environ Chang 18:2073-2087. https://doi.org/10.1007/s10113-018-1326-6

Jones L, Tanner T (2017) 'Subjective resilience': using perceptions to quantify household resilience to climate extremes and disasters. Reg Environ Chang 17:229-243. https://doi.org/10.1007/s10113016-0995-2

Kaiser HF (1970) A second generation little jiffy. Psychometrika 35:401415

Keating A, Handmer J (2011) Options for assessing the cost of climate change for adaptation policy in Victoria (no. working paper 2)

Keating A, Campbell K, Mechler R, Magnuszewski P, Mochizuki J, Liu W, Szoenyi M, McQuistan C (2016) Disaster resilience: what it is and how it can engender a meaningful change in development policy. Dev Policy Rev 35:65-91 http://pure.iiasa.ac.at/id/eprint/11897/

Keating A, Campbell K, Szoenyi M, McQuistan C, Nash D, Burer M (2017) Development and testing of a community flood resilience measurement tool. Nat Hazards Earth Syst Sci 17:77-101. https:// doi.org/10.5194/nhess-17-77-2017

Kok M, Lüdeke M, Lucas P, Sterzel T, Walther C, Janssen P, Sietz D, de Soysa I, Lü deke M, Lucas P, Sterzel T, Walther C, Janssen P (2016) A new method for analysing socio-ecological patterns of vulnerability. Reg Environ Chang 16:229-243. https://doi.org/10.1007/ s10113-014-0746-1

Lam NS-N, Qiang Y, Arenas H, Brito P, Liu K (2015) Mapping and assessing coastal resilience in the Caribbean region. Cartogr Geogr Inf Sci 42:315-322. https://doi.org/10.1080/15230406.2015. 1040999

Lam NSN, Reams M, Li K, Li C, Mata LP (2016) Measuring community resilience to coastal hazards along the northern Gulf of Mexico. Nat Hazards Rev 17. https://doi.org/10.1061/(ASCE)NH.1527-6996. 0000193 
Luthar SS (2006) Resilience in development: a synthesis of research across five decades. In: Cicchetti D, Cohen DJ (eds) Developmental psychopathology: risk, disorder, and adaptation, vol 3, 2nd edn. Wiley, Hoboken, pp 739-795

Manyena SB (2006) The concept of resilience revisited: the concept of resilience revisited. Disasters 30:434-450. https://doi.org/10.1111/j. 0361-3666.2006.00331.x

Mayunga JS (2007) Understanding and applying the concept of community disaster resilience : a capital-based approach, in: summer academy for social vulnerability and resilience building. Munich, Germany, pp 1-16

McNeil AJ, Frey R, Embrechts P (2015) Quantitative risk management: concepts, Techniques and Tools-revised edn. Princeton University Press, Princeton

Mechler R (2016) Reviewing estimates of the economic efficiency of disaster risk management: opportunities and limitations of using risk-based cost-benefit analysis. Nat Hazards 81:2121-2147 pure.iiasa.ac.at/11929

Nardo M, Saisana M, Saltelli A, Tarantola S, Hoffman A, Giovannini E (2005) Handbook on constructing composite indicators, OECD Statistics Working Papers https://doi.org/10.1787/533411815016

Norris FH, Stevens SP, Pfefferbaum B, Wyche KF, Pfefferbaum RL (2008) Community resilience as a metaphor, theory, set of capacities, and strategy for disaster readiness. Am J Community Psychol 41:127-150. https://doi.org/10.1007/s10464-007-9156-6

Ostadtaghizadeh A, Ardalan A, Paton D, Jabbari H, Khankeh HR (2015) Community disaster resilience: a systematic review on assessment models and tools. PLoS Curr 7. https://doi.org/10.1371/currents.dis. f224ef8efbdfcf1d508dd0de4d8210ed

Parsons M, Glavac S, Hastings P, Marshall G, McGregor J, McNeill J, Morley P, Reeve I, Stayner R (2016) Top-down assessment of disaster resilience: a conceptual framework using coping and adaptive capacities. Int J Disaster Risk Reduct 19:1-11. https://doi.org/10. 1016/j.ijdrr.2016.07.005

Rose A (2009) CREATE research archive economic resilience to disasters (no. Paper 75), CARRI Research Report, Published Articles \& Papers

Schipper L, Langston L (2015) A comparative overview of resilience measurement frameworks analysing indicators and approaches. Overseas Development Institute working paper, Overseas Development Institute, London [WWW document]. ODI work. Pap. 422. https://www.odi.org/sites/odi.org.uk/files/odi-assets/ publications-opinion-files/9754.pdf. Accessed 5.5.18
Sendzimir J, Magnuszewski P, Flachner Z, Balogh P, Molnar G, Sarvari A, Nagy Z (2008) Assessing the resilience of a river management regime: informal learning in a shadow network in the Tisza River Basin. Ecol Soc 13:art.11

Sharifi A (2016) A critical review of selected tools for assessing community resilience. Ecol Indic 69:629-647. https://doi.org/10.1016/j. ecolind.2016.05.023

Shaw M (2006) Community development and the politics of community. Community Dev J 43:24-36. https://doi.org/10.1093/cdj/bs1035

Spector S, Cradock-Henry NA, Beaven S, Orchiston C (2019) Characterising rural resilience in Aotearoa-New Zealand: a systematic review. Reg Environ Chang 19:543-557. https://doi.org/10. 1007/s10113-018-1418-3

Tambo JA, Wünscher T (2017) Enhancing resilience to climate shocks through farmer innovation: evidence from northern Ghana. Reg Environ Chang 17:1505-1514. https://doi.org/10.1007/s10113017-1113-9

Twigg J (2009) Characteristics of a disaster-resilient community: a guidance note (version 2). Teddington, UK

UNISDR (2015) Sendai framework for disaster risk reduction 2015 2030. Third United Nations World Conf. Disaster Risk Reduct. 125. A/CONF.224/CRP.1

Welsh M (2014) Resilience and responsibility: governing uncertainty in a complex world. Geogr J 180:15-26. https://doi.org/10.1111/geoj. 12012

Wilson GA (2008) From "weak" to "strong" multifunctionality: conceptualising farm-level multifunctional transitional pathways. J Rural Stud. https://doi.org/10.1016/j.jrurstud.2007.12.010

Wilson GA (2010) Multifunctional "quality" and rural community resilience. Trans Inst Br Geogr 35:364-381. https://doi.org/10.1111/j. 1475-5661.2010.00391.x

Wilson GA (2014) Community resilience: path dependency, lock-in effects and transitional ruptures. J Environ Plan Manag. https://doi. org/10.1080/09640568.2012.741519

Zurich Flood Resilience Alliance internal report (2017) First insights from the flood resilience measurement tool baseline data. Laxenburg, Austria

Publisher's note Springer Nature remains neutral with regard to jurisdictional claims in published maps and institutional affiliations. 